\title{
Welcome to the Real World
}

\author{
Escaping the Sociology of Culture and Cognition
}

\author{
Stephen Vaisey ${ }^{*}$
}

15 July 2021

\section{Introduction}

Virtual worlds are a staple of modern fiction. In The Matrix, The Truman Show, Westworld, and many other works, the protagonist begins by thinking she is living an ordinary life. But something, she realizes, is not quite right. She soon discovers that her world is not the real one, but a simulation maintained by some malevolent force. The details vary, but the story typically culminates in her painful escape into the real world.

I want to persuade you that "the sociology of culture and cognition" is a virtual world and thatalthough it will be painful-we should try to escape.

Unfortunately there are two things that will make escape even harder for us than for a fictional protagonist. First, we have no malevolent enemy-we have trapped ourselves. Second, a fictional protagonist eventually finds out she is more important and special than she thought. But in our case, escaping means realizing we are much less important than we believed.

\section{The Comtean Simulation}

What are the grounds for claiming that the sociology of culture and cognition is a "virtual world?" At first glance, it seems real enough. It is a subfield that "address[es] how aspects of culture (e.g., beliefs, norms, practices, frames, schemata, symbols, and values) as well as various elements of social structure (e.g., network configurations, power arrangements, and the organization of institutions) impact the ways in which social actors think" (Cerulo 2015). Of course, this is a big area for one group of sociologists to cover. To their credit, most of the pioneers of the sociology of culture and cognition (Cerulo 2002; e.g., DiMaggio 1997) acknowledged that we would not be able to succeed without the expertise of other disciplines.

\footnotetext{
^Duke University, Departments of Sociology and Political Science, stephen.vaisey@duke.edu
} 
But here's the catch: most sociologists don't really get interdisciplinarity. Whether we acknowledge it or not, most of us have internalized a sociological supremacy that makes us believe our field's insights are more important, more complete, more nuanced than those of other scientists (Healy 2017). This cultural background of intellectual superiority helps create what Omar Lizardo (2014) called the "Comtean schema" - the implicit belief that all proper interdisciplinary research should take the institutional form of a subfield of sociology.

In a brilliant insight, Lizardo noted that sociologists create virtual "avatars" of other disciplines within sociology instead of working with their real-world counterparts. That is, rather than engage with economists, we create "economic sociology"; rather than engage with political science, we have "political sociology"; rather than engage with cultural evolution or cognitive science, we invent "the sociology of culture and cognition." And so on. This fools us into thinking that we're being interdisciplinary when, in reality, "[t] hese subdisciplinary avatars have been created by sociologists for sociological consumption” (Lizardo 2014:985).

Lizardo was perhaps the first to realize we're living in a virtual world-a Comtean simulation. What was his recommendation? To escape. To abandon "the sociology of culture and cognition" and join the interdisciplinary "cognitive social science" that was already coming into being without a meaningful contribution from sociology. Seven years later, we know much more about what that cognitive social science looks like. And how are things going in sociology?

I consider this question in two ways. First, I focus on a particular case study-the study of values. Although my argument about the Comtean simulation is meant to be generally applicable, some aspects can only be studied in the context of a particular topic. The current debate in cultural sociology on values is an excellent case. Second, I examine more general (non-topic-specific) mechanisms that dissuade sociologists from doing truly interdisciplinary work. I will conclude by outlining some possibilities that I believe we are currently missing.

\section{The Case of Values}

\subsection{Values and Cultural Sociology}

One place where cultural sociologists have started to engage the outside world is the study of values (see e.g., Miles 2015). Sociologists' relationship to values has a complex history. Wuthnow (2008:334) outlines three main phases of values research in postwar U.S. sociology: concept development and empirical study from the 1950s to the 1970s; criticism and retrenchment in the late 1970s to the 1980s; and a "roaring comeback" starting in the 1990s.

Although values did make a relatively early comeback in some areas of sociology (Hitlin and Piliavin 2004; e.g., Inglehart and Baker 2000), this took much longer in cultural sociology. From the late 1980s well into the mid-2000s, the dominant theory of culture was Swidler's (1986) "toolkit" model, which explicitly rejected values. If anything, until recently, cultural sociologists seemed to feel obligated to disavow values. As late as 2008, for example, Michèle Lamont and Mario Small outlined six elements of culture (frames, repertoires, narratives, symbolic boundaries, cultural capital, 
and institutions), carefully clarifying how each one was not values (Lamont and Small 2008). ${ }^{1}$

Among U.S. cultural sociologists, the first major connection to the contemporary interdisciplinary literature on values came in the mid-2010s with Andrew Miles's (2015) paper in the American Sociological Review, "The (Re)genesis of Values." During sociology's long hiatus from values, most work in this area had coalesced around Schwartz's theory of basic human values (Schwartz et al. 2012). This theory posits a continuous circumplex of opposing values that can be heuristically divided into $2,4,10,19$, or even more categories depending on researcher goals and measurement precision [Schwartz and Cieciuch (2021); see Figure 1]. I will discuss this literature more below. But, in brief, Miles used theory along with observational and experimental evidence to argue that sociologists would benefit from engaging with values research if they want to develop an accurate and empirically useful model of how culture influences human behavior.

Miles's paper has been cited over 130 times $^{3}$ as of June 2021. Although most of the citations are from outside of cultural sociology, there is evidence that at least some cultural sociologists are paying attention and willing to engage (e.g., Lizardo et al. 2016).

\subsection{Resisting Values}

Not all cultural sociologists, however, are willing to welcome values back to the fold. A recent paper in the American Journal of Sociology by Martin and Lembo (2020), "On the Other Side of Values," pushes back explicitly against Miles's argument, claiming that sociologists should reject values once and for all. If sociologists want to develop a theory of action, the authors argue, we should look inward to our own disciplinary traditions (and perhaps to some 19th- and early 20th-century philosophers), rather than outward to interdisciplinary work on values.

This renewed debate about values provides an excellent case study for understanding cultural sociologists' relationship with interdisciplinarity. Although "On the Other Side of Values" was published less than a year ago (as of June 2021), it has already been cited 15 times. Of course it is too early to judge the paper's ultimate impact. But it seems likely that it will serve as the most prominent articulation of sociologists' case against values. ${ }^{4}$ Even if it does not become a citation classic, "On the Other Side of Values" includes, in addition to its original contributions, the strongest version of arguments cultural sociologists have been making against values for three decades.

If interdisciplinarity is generally a good thing, why do Martin and Lembo (hereafter M\&L) believe we should reject values? I consider their arguments in detail.

\footnotetext{
${ }^{1}$ A later version of this paper (Small, Harding, and Lamont 2010) did add values to the list, albeit with a host of disclaimers, perhaps because it served as an introduction to a special issue that contained a paper on values (Vaisey 2010).

${ }^{2}$ There were several relevant precursors to Miles's work, but they were either tangential to historical debates on culture (e.g., Hitlin and Piliavin 2004; Longest, Hitlin, and Vaisey 2013), disconnected from the interdisciplinary scientific tradition (e.g., Joas 2000; Vaisey 2010), or insufficiently empirical (e.g., Hitlin and Vaisey 2013; Vaisey and Miles 2014).

${ }^{3}$ According to Google Scholar.

${ }^{4} \mathrm{~A}$ forthcoming Annual Review on socialization by cultural sociologists (Guhin, Calarco, and Miller-Idriss 2021) provides a telling illustration. After approvingly discussing Miles's work on values, the authors add parenthetically "but see Martin and Lembo (2020) for a critique of values."
} 


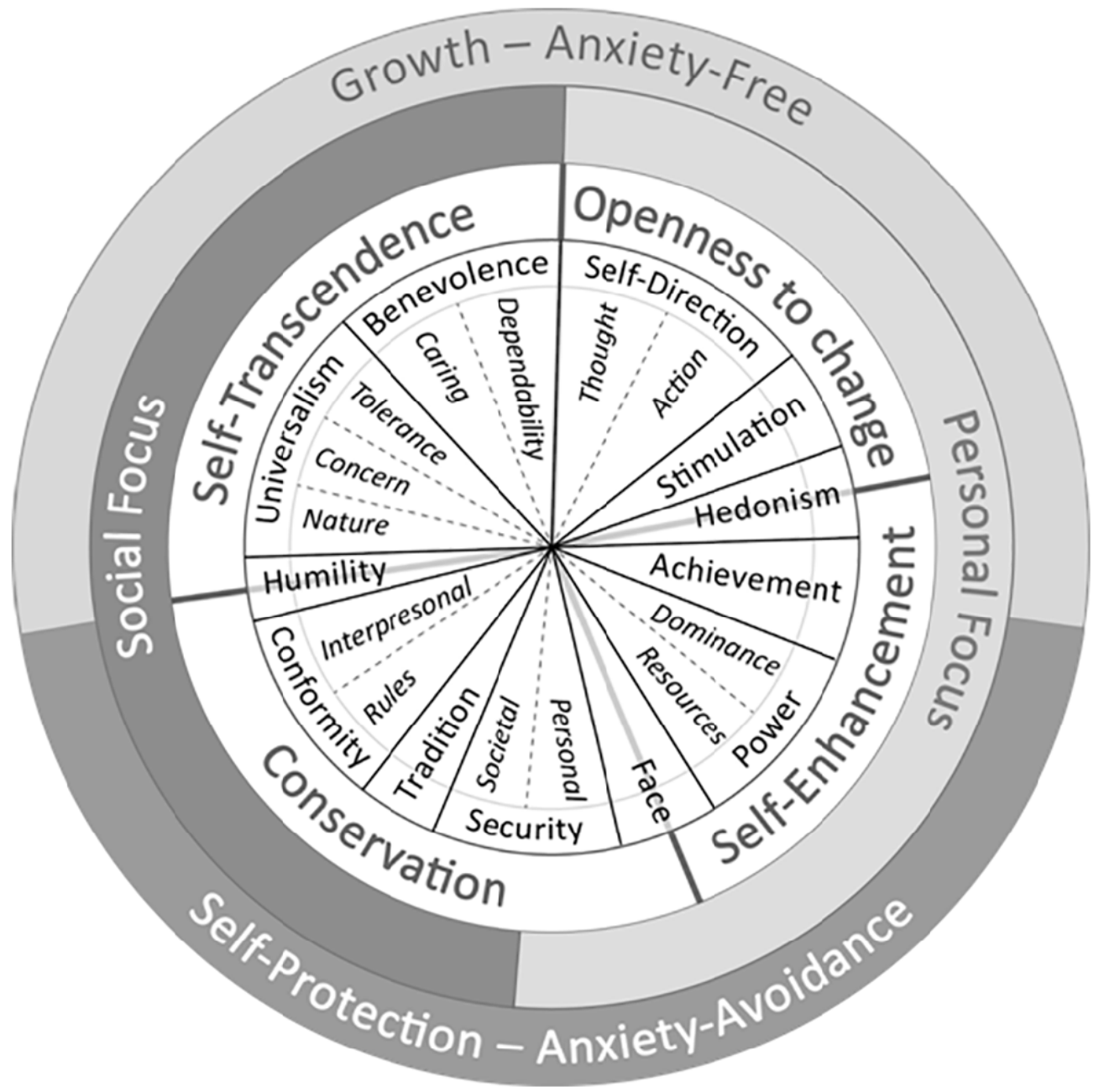

Figure 1: The Schwartz values circumplex (from Schwartz and Cieciuch 2021) 
I want to concede two of M\&L's points right away. First, they are right that any concept of values that regard them as universally shared are unjustified. Second, they are also right that positing values as inherently opposed to self-interest is incoherent. I couldn't agree more. But most contemporary values researchers would probably also agree. Despite the authors' attempts to connect these faults to "values" per se, they only succeed in attributing them to Talcott Parsons. Most of the points they make about Parsons's thought have little relevance for contemporary values research.

Though often invoking Parsons, M\&L acknowledge that most values research today is informed by Shalom Schwartz's theory of basic human values (see above). Fortunately this theory avoids the two Parsonian problems noted above: first, Schwartz's theory is explicitly focused on value diversity between and within societies, and second, Schwartz's theory allows "self-interested" motives like self-direction and achievement to be legitimate bases for valuation. Most (if not all) of the other modern traditions in moral or cultural psychology are similar in this respect (Graham et al. 2011; e.g., Inglehart and Baker 2000). To accept values is not necessarily to accept Talcott Parsons.

But M\&L still see contemporary work on values as fatally flawed. Their argument is wide ranging, but I distill it into three principal objections and consider each in turn.

1. Values neither predict behavior nor come up in ordinary moral discourse

2. Values-as-measured are nothing but desires or personality

3. Abstract values are not real; concrete interests are

The goal of evaluating this argument is to determine whether sociologists should shun the interdisciplinary study of values and in favor of a home-grown alternative. In my discussion of values, I will focus on Schwartz's work where possible because it is the most prominent tradition in the study of values and is the most prominent intellectual connection with contemporary cultural sociology (via Miles 2015). But I will occasionally draw on other resources from moral psychology or cross-cultural values research where useful.

\subsubsection{Behavior and accounts}

Cultural sociologists often claim that mental constructs like attitudes and values fail to predict behavior (Jerolmack and Khan 2009; e.g., Swidler 1986). This is also where M\&L begin. But this is not an accurate summary of the literature. I have covered this topic in great detail elsewhere (Vaisey 2014; see also Lee et al. 2021). Here, I will simply state that values (along with attitudes, intentions, and so on) generally predict behavior more accurately than most of the things sociologists study (e.g., parental SES). The studies sociologists typically cite to support these claims (e.g., LaPiere, Milgram, Myrdal; see Martin and Lembo 2020) are very old, methodologically weak, highly specific, and often contested (see, e.g., Blass 1991; Perry et al. 2020). Although evocative, they cannot be used to support an overall claim that values are irrelevant to behavior.

M\&L go further. Not only do values fail to predict what people will do, they argue, values are not even a cultural resource people use to talk about what they should do (Martin and Lembo 2020:58). Or, if they do, this sort of talk is simply for self-justification among educated moderns rather than a reflection of a universal set of categories for making moral claims on others (71). 
This claim is also not completely consistent with the evidence. Moral and evaluative language has been studied extensively "in the wild" and this is a massively growing research area thanks in part to the explosion of big data (e.g., Iliev, Dehghani, and Sagi 2015; Ponizovskiy et al. 2020). There is also a much more robust connection between socially produced language and psychological traits than M\&L's skeptical take suggests. It is possible, for example, to predict a person's responses on morality questionnaires on the basis of the language they naturally produce (see e.g., Kennedy et al. 2021).

Schwartz's theory has also been examined in settings far beyond those of educated moderns. Indeed, versions of the Schwartz values questionnaire have been fielded in more than 75 countries and discovered similar results (Cieciuch, Schwartz, and Davidov 2015:44). They dimensions the theory posits are not limited to WEIRD societies. ${ }^{5}$

There is much more work to do in this area. Specifically, we would benefit from a greater integration of Schwartz values with computational work (see Ponizovskiy et al. 2020) and the extension of textbased work to non-WEIRD societies. But even now we have reasonably good evidence that values (whatever they are; more below) are meaningfully related to action, cognition, self-expression, and interpersonal persuasion.

\subsubsection{Morality and personality}

The second objection is that the "downward" shift from values-as-universals to values-as-individualdifferences destroys anything distinctive about values. There are two major bases for this claim. The first is that value schemes (like Schwartz's) capture an arbitrary set of preferences rather than anything specially moral. The second is that the method of measurement - usually self-comparison to a hypothetical individual - means that measures of values are simply measures of personality. I consider each.

First, M\&L seem to find Schwartz's typology laughably arbitrary. (Among other things, they claim Schwartz forgot to add a "chorizo" indicator to measure the "Fat dimension" [p. 59]. This sounds like mockery.) They assert this arbitrariness without engaging seriously with any of the hundreds of empirical studies that provide evidence for it (Cieciuch, Schwartz, and Davidov 2015:44). The theoretical basis for values is that they are not a collection of random preferences (like for vanilla or chocolate ice cream) but are grounded in

...three universal requirements of human existence: needs of individuals as biological organisms, requisites of coordinated social interaction, and survival and welfare requirements of groups (Cieciuch, Schwartz, and Davidov 2015:45)

Moreover, the circular structure of values implies necessary trade offs and conflicts and the impossibility of harmonization, something M\&L $(63,88)$ praise in Weber's approach to values.

One can, of course, debate these theoretical assumptions. And we should. But it is not unreasonable to think that, for example, the tension between self-enhancement and group coordination is

\footnotetext{
${ }^{5}$ WEIRD stands for Western, Educated, Industrialized, Rich, and Democratic (see Henrich, Heine, and Norenzayan 2010).
} 
fundamental to human social life (Olson 1965) and that individuals and social groups might develop characteristic ways of dealing with these tensions (see O'Connor 2019). Equating these sort of concerns with "the desire to eat human flesh" or "a rock rolling downhill" is an uncharitable misreading of Schwartz's argument. ${ }^{6}$ All the major theories of values explicitly articulate "the validity qualification" M\&L (2020:67) claim is missing (see Hitlin and Piliavin 2004:362). ${ }^{7}$

The second issue they raise is more specifically about measurement. Because Schwartz's values are usually measured by asking respondents to compare themselves to hypothetical persons, M\&L argue that the Portrait Values Questionnaire is simply measuring personality rather than perceived moral importance. They claim that these purported "values" are thus nothing more than "desires." But the Schwartz circumplex is reliably found in data regardless of the method of measurement. For example, a recent study using paired comparisons of perceived "importance" shows the circumplex predictions of the theory work equally well (Lee et al. 2019).

M\&L (88) also assert that the most obvious candidates for justified moral persuasion-"fairness" and "humanity"- have "never been included in a sociological value inventory." This doesn't seem quite right. The items from Schwartz Portrait Values Questionnaire (Schwartz and Cieciuch 2021) that seem relevant ask whether it's important for the respondent

- ... that the weak and vulnerable in society be protected

- ... never to think she deserves more than other people

- ... to be tolerant toward all kinds of people and groups

- ... to listen to and understand people who are different from her

- ... that every person in the world have equal opportunities in life

- ... to accept people even when she disagrees with them

These are all indicators of what Schwartz's theory would call self-transcendence and/or universalism, depending on measurement precision. It seems to me there is decent coverage here of both "fairness" and "humanity." Overall, then, I believe M\&L's attempts to equate Schwartz's values with a random or theoretically arbitrary subset of "personality" or "desires" are unpersuasive.

\footnotetext{
${ }^{6}$ There is, in fact, a strong similarity between Schwartz's theory of values and sociologist W.I. Thomas's classification of "the four wishes" (Thomas 1923:1-40). Thomas posited the following "general classification" of "human wishes": 1) the desire for new experience; 2) the desire for security ("opposed to the desire for new experience") ; 3) the desire for response ("love"); and the desire for recognition ("status"). These are almost (if not totally) identical, respectively, to Schwartz’s 1) openness to experience; 2) conservation; 3) self-transcendence; and 4) self-enhancement.

${ }^{7} \mathrm{M} \& \mathrm{~L}$ note that recent sociological references to values omit the validity qualification. For evidence, they cite several recent sociological works (including my own) that cite Kluckhohn's (1951) phrase "conceptions of the desirable" without explicitly referencing his assertion that these conceptions need to be justified. This is a fair critique but does not apply to Schwartz's work on values.
} 


\subsubsection{Interests and abstraction}

M\&L's final point builds on the first two, asserting that the word "values" simply refers to nothing real in the world. What is real, they argue, is the experience of "taking an interest" in something. They conclude that we should thus abandon the study of values and embrace the study of concrete interests.

What is the difference between a value and an interest? This passage provides a good sense of M\&L's position:

Hitlin and Piliavin (2004) argue that the value that sex expresses is love; sex, they declare, is not a value but love is. [John] Dewey's [...] perspective suggests that neither sex nor love is the sort of thing that might bear this value, while another person-the object, say, of sexual/romantic desire/love - can indeed be valuable. Such an emendation [...] would leave us with a concept that is [...] closer to what is commonly meant by interests, and we suggest that if we replace the term values with interests, Dewey's core insights $[\ldots]$ are only clarified (76-77).

Their main objection therefore seems to be that values are a "hypostasized plural noun" (55) lacking in concrete reality. It is therefore meaningless to say, for example, "I value self-direction," but it might be reasonable to say "I am interested in owning a bar."

There are at least three responses to this objection. First, Schwartz value theory does not, in fact, posit a set of discrete values but a continuous circumplex analogous to the color wheel. We discretize values for convenience, much like we might call light with a wavelength between 620 and 750 nanometers "red." So in Schwartz's theory, the value space (for want of a better word) is real-the existence of inescapable tensions in social life-but the individual value names are just heuristics. This space may also debatable, of course, but it is not vulnerable to M\&L's concreteness critique.

A second response requires a broader reflection on abstraction and generalization. Questions about natural kinds are ancient. Is the category "chair" real or just a collection of particular objects we call "chair?" Perhaps like most social scientists, I am less interested in the metaphysics than in understanding how humans make such generalizations. This process has long been an object of cognitive and cultural research outside sociology (Brand, Mesoudi, and Smaldino 2021; see e.g., Shepard 1987; Tenenbaum and Griffiths 2001).

This is not the place to review an extensive literature, but a couple of points are worth noting. First, there is good evidence that abstractions are computationally useful for problem solving in humans as well as in other natural and artificial systems (Ho et al. 2019). Second, we can not only use comparisons to learn how two stimuli are related in a known similarity space (e.g., distance, weight) but also to learn which hypothesis space is most relevant for the comparison of two stimuli (Austerweil, Sanborn, and Griffiths 2019). For our purposes, this suggests that most enculturated adults in our society will have no trouble understanding how, for example, jointly experiencing an "interest in going to the ASA meetings" and an "interest in taking care of my sick child" belongs to the category "work-family conflict" (i.e., achievement vs. benevolence) rather than to the category, say, "homesickness." 
The perceptible features of our concrete interests allow us to generalize from them in useful ways. Instances requiring trade-offs between our own desires and the desires of those in whom we are "invested" (Martin and Lembo 2020:79) have features in common. Generalizing from these instances allows us to make predictions about future situations. In this sense, all generalization is "transdyadic" in the sense M\&L criticize (see Martin and Lembo 2020:76). Abstractions like "achievement" or "autonomy" (not to mention more prosaic generalizations like "I like dancing") help us learn from experience and make decisions. ${ }^{8}$

A third response would be to ask M\&L for an alternative account of the empirical pattern of results from Schwartz values research. How does their interest framework make sense of the fact that many thousands of people, in at least 75 different countries, over three decades, using different measurement tools, collected by different investigators, have repeatedly found essentially the same circumplex pattern? Given the sheer diversity of the societies involved, invoking the justification practices of educated moderns is insufficient. Respondents from highly diverse social contexts have little trouble recognizing a specific pattern of tension in the Schwartz value items. Some kind of consistent intraindividual generalization is happening (Gollan and Witte 2014). M\&L's insistence on the concreteness of interests cannot, as far as I understand it, make sense of this.

\subsubsection{What M\&L Get Right}

Taking values seriously is still compatible with several aspects of M\&L's argument, in addition to the two points I conceded above. First, they are probably right to be skeptical that values are "abstract beliefs" (54), a claim that values researchers often make (e.g., Hitlin and Piliavin 2004:362). Values may instead be more akin to music genres, dog breeds, or occupational classifications in that they combine "bottom up" and "top down" categorization processes. (Analogously, color terms vary some across societies but we wouldn't call our tendency to classify something as "blue" an abstract belief.) Nevertheless, implicit cognition of this sort is still capable of having structure and of motivating action.

Second, M\&L are also probably correct that self-involving experiences of intension, attention, and extension (84) are all necessary parts of the phenomenology of valuation (see Joas 2000). Yet recognizing the phenomenology of valuing a concrete object isn't a problem for values any more than the phenomenology of listening to a specific song is a problem for musicology. They are simply different questions.

Both of these insights would make a useful intervention in the values literature. But neither is a persuasive argument against the use of values in general or against Schwartz's theory in particular.

\subsection{A Fork in the Road}

Values is just one element of culture, but it is one that has inspired a great deal of discussion and debate among cultural sociologists. As a case study, the emerging debate between Miles (2015) on

\footnotetext{
${ }^{8}$ Of course there is some flexibility in judging "what is this a case of?" Other people's interpretations and feedback will be features of the situation that might affect our own categorizations. Social feedback is even probably "special" in its ability to influence learning (Ho et al. 2017).
} 
the one hand and Martin and Lembo (2020) on the other can be understood more generally as a microcosm of contrasting visions of what cultural sociology should be. In their introductory essay in the Oxford Handbook of Cognitive Sociology, Brekhus and Ignatow (2019:2) describe the opposition between what they call "the respective visions of Zerubavel and DiMaggio." These conflicting visions either aim to develop a self-sufficient "sociological" approach to cognition on the one hand (Zerubavel) or to contribute to an interdisciplinary cognitive social science on the other (DiMaggio).

Miles invites cultural sociologists to join a thriving interdisciplinary conversation on values. Martin and Lembo tell us that the answers we need can be only found in our own intellectual tradition, perhaps supplemented by close readings of Dewey, Kant, or Tarde. For cultural sociologists making decisions about their careers, it can be difficult to decide which advice to take. But decide they must. Ultimately, whether it be about values, norms, socialization, beliefs, categorization, or any other topic, there is no substitute for diving into the literature and forming one's own judgment.

\section{More General Mechanisms}

The previous section examined a specific intellectual debate about values. This required a close examination of specific arguments. But not all mechanisms that inhibit interdisciplinary engagement take the form of explicit claims about a well-defined topic. In this section, I consider other mechanisms that tend to reinforce the boundaries of the Comtean simulation in cultural sociology across a wide range of topic areas.

\subsection{Simple Omission}

Cultural sociologists' lack of interdisciplinary engagement can be-and probably usually isinadvertent. If we read and publish research that omits scholarship from outside sociology then our own work will perpetuate our intellectual isolation. This leads to an "out of sight, out of mind" problem where even scholars with explicitly pro-interdisciplinary views miss out on possible connections.

One otherwise excellent case that exemplifies this sort of mechanism is the new book, Measuring Culture, by John Mohr (1959-2019), Christopher Bail, Margaret Frye, Jennifer Lena, Omar Lizardo, Terence McDonnell, Ann Mische, Iddo Tavory, and Frederick Wherry (2020). ${ }^{9}$ The book is a fascinating deep dive into how cultural sociologists think about and go about their research. If the book was called Doing Cultural Sociology, I would have nothing but praise for it. But for a book that claims to take up the question "how, then, should we study [culture] as social scientists?" (2), it is quite narrow in its focus on cultural sociologists and their mid-20th-century intellectual antecedents.

The book's introduction claims that "in its current iteration, the study of culture is most strongly associated with the subfield of cultural sociology" (2, emphasis in original). Respectfully, I don't believe this is an accurate characterization of the diversity of contemporary culture scholarship.

\footnotetext{
${ }^{9}$ Full disclosure: I was a participant in this project from its origins in 2013 until I left in July 2017. I consider myself good friends with every one of the authors and it was one of the most fun and interesting experiences of my early career.
} 
Measuring Culture describes methodological and measurement strategies for three types of culture: in persons, in objects, and in social relations. On the measurement of culture in persons, the book contains only a single (footnote) reference to Schwartz's work on values. It contains no references at all to the field of cultural psychology (see Kitayama and Cohen 2007), even as that field has explicitly begun investigating class, race, religion, and other categories sociologists care about (Oyserman 2017). It omits any reference to technical issues of measurement, including validity, reliability, or cross-cultural equivalence, even from other subfields in sociology (e.g., Davidov et al. 2014).

On the measurement of culture in objects, the book is solidly focused on the research of cultural sociologists. To their credit, the authors of Measuring Culture are explicitly open "to future collaboration with natural and human scientists" (70). But they miss the opportunity to make existing connections, however briefly. For example, in their discussion of object affordances, the authors could have engaged with research and theory in ecological psychology and technology design, where the affordances of social media platforms are a growing object of study (see Evans et al. 2017). This research explicitly regards affordances as relations between objects and agents and is eminently compatible with the research agenda set out in Measuring Culture (Chemero 2003).

Finally, on the measurement of culture in social relations, the authors focus primarily on networks and fields. On these topics, the discussion is perhaps more comprehensive because so much of this work emerged out of sociology. But networks and fields are not the only kinds of social relations. For example, the chapter does not discuss how cultural conventions and instititutions can emerge from social interaction to solve coordination problems (Ostrom 2000; Skyrms 1996) or create categorybased inequality (e.g., O’Connor 2019).

No book can do everything, of course. That's not a reasonable standard. Despite invoking specific examples above, I don't begrudge the authors any particular omission. The pool of potential connections is essentially infinite. My concern is that Measuring Culture defines its object of inquiry very broadly but is ultimately a book by cultural sociologists, for cultural sociologists, and about cultural sociologists. This is not in itself a bad thing! But given the general way the book is framed, I can't help but see it in part as an opportunity missed to broaden the discussion. Some who read the book might not understand that this is only a very small and selective sample of how social scientists are measuring and studying culture in their research.

\subsection{Misunderstandings}

Another mechanism is our misunderstandings about what other "cognitive" disciplines are like. Sociologists usually consider psychology, for example, to be more reductionist or universalist in aspiration than it actually is (see Zerubavel 1997:3). Even though some psychologists are interested in only universals, psychology today is very open to social construction of many kinds and much more suspicious of universalist claims than in the past (see Henrich, Heine, and Norenzayan 2010; Muthukrishna et al. 2020). If anything, contemporary cultural psychology is more attentive to cultural diversity than cultural sociology, which is almost entirely based on data from the U.S. and Western Europe.

Another misconception is that other scholars who study cognition only do lab experiments on college students or online convenience samples. Although they probably do these things more than 
sociologists, it is by no means the exclusive research practice. In the interdisciplinary field of cultural evolution, for instance, researchers do everything from ethnography to mathematical modeling to field experiments to surveys to historical research to "big data" and beyond (Brand, Acerbi, and Mesoudi 2019; Henrich and Muthukrishna 2021; e.g., Mesoudi 2011).

Lauren Valentino and I have written about how misunderstandings like these prevent us from engaging the judgment and decision sciences (Vaisey and Valentino 2018). If cultural sociologists believe that choice researchers in other fields assume that people have complete information, unlimited computational ability, only care about money, and ignore social context, we will not see them as possible resources or collaborators. But all of these ideas are under active debate and study. Even though the language may be different, cultural sociologists have more in common with these scholars than we often realize.

\subsection{Misaligned Incentives}

A final mechanism is institutional. Fields like sociology—and subfields like cultural sociology-are made up of organizations, sections, journals, prizes, networks, and so on. Although most scholars endorse interdisciplinarity in theory, the strong nature of fields makes doing actually interdisciplinary research an uphill climb.

For graduate students and assistant professors, the main impediment is the risk that innovative interdisciplinary work simply won't be understood or valued by journal reviewers or hiring departments. This is a real concern given how anxiety-provoking the job market already is.

For senior faculty, the dynamics are more subtle. By the time a cultural sociologist becomes a full professor, she has become embedded in a network of other sociologists. For some, this means citations, speaking invitations, prizes, and-perhaps most important-status deference. To put it bluntly, at the ASA meetings, people recognize me; at the Cultural Evolution Society or Cognitive Science Society conference, they don't. If, as Randall Collins claims, we seek out successful interaction rituals, I can see why hanging out exclusively with sociologists is a hard habit to break. Why would I want to feel invisible?

That said, the existence of these interdisciplinary organizations at least provides a starting place. At the time of writing, there are only a handful of sociologist members of either the Cultural Evolution Society or the Cognitive Science Society. Membership in these organizations is much, much less expensive than ASA and provides exposure to more focused interdisciplinary dialogue.

In addition to taking these small steps, I think we need be thoughtful about career stages. My sense is we expect innovation from younger scholars and solid contributions to established research agendas from older scholars. I think we would all benefit by senior faculty being a bit more adventurous. If we were more willing to use our job security to take intellectual risks instead of consolidating our expertise, we would likely see more interdisciplinary and innovative work. 


\section{What Are We Missing?}

I have made the argument that cultural sociologists are living in their own virtual world-the Comtean simulation - and that they should try to escape to the "real world" of the interdisciplinary cognitive social sciences. I have outlined what I see as key mechanisms that keep many of us happily imprisoned. My hope is that considering this argument might cause you to question whether you want to stay or make a break for it.

One good skeptical response to my argument is that this "outside world" is no more "real" than cultural sociology itself. Aren't they also failing to reach out to us? The simple answer is yes. However, for better or for worse, there are a lot more of them than there are of us. Researchers from behavioral economics, computer science, evolutionary and cultural anthropology, neuroscience, philosophy, politics, psychology, and other fields are talking with each other about things sociologists would consider central to "culture and cognition." For the most part, despite their differences, they have learned to at least speak the same language (Buyalskaya, Gallo, and Camerer 2021; Vaisey and Valentino 2018).

The only possible justification for staying out of this "golden age of social science" (Buyalskaya, Gallo, and Camerer 2021) is the belief that they-but not us-are all on the wrong track. Unless we are willing to assert that all these scholars are irredeemably confused because they didn't read Marx, Weber, and Durkheim in graduate school, I think we're missing out by not joining the party. Ingroup bias is a real thing, but other scholars are no worse-or better-than us. They, like us, are just curious people who learned a partial and particular set of tools and are trying to figure out the world. Escaping the Comtean simulation means realizing our discipline-like all the others-is nothing special.

The "real world" as I have described it is a very big place. Making every connection would be impossible for a field, much less for any single researcher. I therefore briefly outline here a few promising places where I think sociologists could jump in to ongoing conversations and help "continue the story" (Cerulo 2014). This list is by no means complete, but I hope helps serve as a starting point for those who are interested.

\subsection{Values}

Most obviously, I think sociologists have a lot to gain by working with (among others) psychologists and political scientists on values. Figuring out how to "dimensionalize" culture is an enterprise shared by many disciplines and research traditions. Political scientists are interested in the structure of political divisions (Feldman 2013; Johnston and Ollerenshaw 2020). Comparativists are interested in understanding cross-national differences (Muthukrishna et al. 2020).

I have argued elsewhere (Vaisey and Miles 2014) that some of our homegrown classifications in cultural sociology are eminently compatible with the values literature. For example, Michèle Lamont's (1992) data on how middle class French and American men draw symbolic boundaries fits the predictions of Schwartz value theory perfectly. The correlations between her respondents' uses of "money" boundaries (self-enhancement), "morals" boundaries (self-transcendence), and "manners" boundaries (stimulation and self-direction) are correlated exactly as you'd expect given the 
Schwartz value circumplex (see Figure 1).

\subsection{Social Learning}

Though many dislike the term because of its functionalist baggage, sociologists are deeply invested in the idea of "socialization" (see Guhin, Calarco, and Miller-Idriss 2021). We know that people do not simply "download" their culture from society, so what learning mechanisms are at work?

Research on prestige-biased social learning (Brand and Mesoudi 2019; Jiménez and Mesoudi 2019; Mesoudi 2020/ed) is an obvious place for sociologists to get involved. This work seeks to understand how learners figure out whom to imitate in their social environments. There are great opportunities here to merge in sociological insights. One early connection can be found in a paper by Edelmann (2019), who draws on the literature on symbolic boundaries to predict that adolescents will disproportionately copy the alcohol use of same-religion peers. These predictions are supported by an analysis of Add Health network data.

More generally, social scientists assume that actors get information from others. But there are large and so-far unexplained differences in how much people use information they get from others. For example, in counting tasks, participants vary in how much they update their estimates based on what others are saying (Molleman, Kurvers, and van den Bos 2019). Building on this research, sociologists could, for example, investigate class and status differences in outside information use using well-developed measurement tools. Recent research in cultural sociology suggests that age might also play a role in how much people use outside information to update (Kiley and Vaisey 2020).

Finally, existing social network data is full of opportunities to investigate hypotheses relevant to ongoing research on social learning. Sociologists can also inject a much-needed class dimension by adding the insights of work like Unequal Childhoods (Lareau 2003) to this discussion.

\subsection{Cultural Change}

We know that culture is never static, but what are the most useful ways to understand cultural change? Work in the cognitive social sciences in this area is vast (see Henrich 2015; Mesoudi 2011) and cultural sociologists have much to learn and to contribute.

Some integration is happening in this area as sociologists begin combining demographic ageperiod-cohort models with theories of cultural evolution (Tormos 2020; Vaisey and Kiley 2021). Some of this research suggests that simple evolutionary models might be insufficient if actors have a "sensitive period" where they are more open to influence. Cohort effects might be a key reason for lingering cultural conflict and the perceived slowness of some types of change in public opinion.

Scholars are also investigating changes in forms of culture like books of music. Sociologists (Koch, Silvestro, and Foster 2020) and non-sociologists (Brand, Acerbi, and Mesoudi 2019) are using evolutionary models to investigate patterns of cultural change. Even in traditionally humanist fields like English, scholars are using computational techniques to understand literary change at massive scale (Underwood 2019). There are so many opportunities for cultural sociologists to get involved in this work. 


\subsection{Categorization and Inference}

Categorization (e.g., music classification) and causal generalizations (e.g., narratives, scripts) are key concepts in cultural sociology. Scholars in cognitive science are actively studying these processes (Tenenbaum et al. 2011; Tenenbaum and Griffiths 2001; Tenenbaum, Griffiths, and Kemp 2006) as well. Unfortunately, integration between the fields has been sparse.

For the most part, cognitive scientists (like those cited above) have used Bayesian models to understand object categorizations (is this an instance of X?) and physical causal models (will this tower fall over?). But sociologists could help push these discussions into the realm of social categorization and social causation. What features do people use to make judgments about race, class, gender, religion, and other social divisions? How do people judge who is likely to be successful (e.g., to go to college)? Some sociological research on online dating platforms has begun to explore these issues at scale (see e.g., Bruch and Newman 2019) but the possibilities here are nearly endless.

\section{Conclusion}

Although claims about a "golden age of social science" (Buyalskaya, Gallo, and Camerer 2021) might be somewhat exaggerated, there is something brewing outside of sociology that is worthy of our attention. I have tried to persuade my fellow cultural sociologists that we should abandon the Comtean simulation of "the sociology of culture and cognition" and venture into the outside world. Lizardo (2014) was right about this in 2014 and his argument is even more applicable today. We have so much to gain by not only reading outside our field, but by actually interacting with, working with, and arguing with other scholars who also want to understand how culture works.

The factors working to keep us entrenched in the world of cultural sociology will be hard to overcome. Some sociologists are genuinely persuaded that sociology is better than other disciplines and they will continue to push us to go it alone. If you are convinced of that, I doubt there's anything I could say to persuade you otherwise. But even for those who are open to interdisciplinarity, there are a host of subtle mechanisms that keep steering us back to cultural sociology's virtual world. For those who are interested in moving beyond the sociology of culture and cognition, joining the Cultural Evolution Society and the Cognitive Science Society seem like the first concrete steps cultural sociologists can take to join the rest of the world.

This isn't going to just happen. To be honest, I am not optimistic about our chances as a field. But I hope that good will, generosity, and curiosity will allow at least some of us to seize our chance to step out into the "real world" of interdisciplinary science of culture and cognition. 


\section{References}

Austerweil, Joseph L., Sophia Sanborn, and Thomas L. Griffiths. 2019. "Learning How to Generalize." Cognitive Science 43(8):e12777. doi: 10.1111/cogs.12777.

Blass, Thomas. 1991. "Understanding Behavior in the Milgram Obedience Experiment: The Role of Personality, Situations, and Their Interactions." Journal of Personality and Social Psychology 60(3):398-413.

Brand, C. O., and A. Mesoudi. 2019. "Prestige and Dominance-Based Hierarchies Exist in Naturally Occurring Human Groups, but Are Unrelated to Task-Specific Knowledge." Royal Society Open Science 6(5):181621. doi: 10.1098/rsos.181621.

Brand, C. O., A. Mesoudi, and P. E. Smaldino. 2021. "Analogy as a Catalyst for Cumulative Cultural Evolution.” Trends in Cognitive Sciences. doi: 10.1016/j.tics.2021.03.002.

Brand, Charlotte O., Alberto Acerbi, and Alex Mesoudi. 2019. "Cultural Evolution of Emotional Expression in 50 Years of Song Lyrics.” Evolutionary Human Sciences 1. doi: 10.1017/ehs.2019.11.

Brekhus, Wayne H., and Gabe Ignatow. 2019. “Cognitive Sociology and the Cultural Mind.” Pp. 1-27 in The Oxford Handbook of Cognitive Sociology, edited by W. H. Brekhus and G. Ignatow. New York: Oxford University Press.

Bruch, Elizabeth, and M. Newman. 2019. "Structure of Online Dating Markets in U.S. Cities." Sociological Science 6:219-34. doi: 10.15195/v6.a9.

Buyalskaya, Anastasia, Marcos Gallo, and Colin F. Camerer. 2021. "The Golden Age of Social Science.” Proceedings of the National Academy of Sciences 118(5). doi: 10.1073/pnas.2002923118.

Cerulo, Karen A., ed. 2002. Culture in Mind: Toward a Sociology of Culture and Cognition. New York: Routledge.

Cerulo, Karen A. 2014. "Continuing the Story: Maximizing the Intersections of Cognitive Science and Sociology." Sociological Forum 29(4):1012-19. doi: 10.1111/socf.12135.

Cerulo, Karen A. 2015. "Culture and Cognition." Pp. 1-22 in Emerging Trends in the Social and Behavioral Sciences. Wiley.

Chemero, Anthony. 2003. "An Outline of a Theory of Affordances." Ecological Psychology 181-95.

Cieciuch, Jan, Shalom H. Schwartz, and Eldad Davidov. 2015. "Values, Social Psychology Of." Pp. 41-46 in International Encyclopedia of the Social \& Behavioral Sciences. Elsevier.

Davidov, Eldad, Bart Meuleman, Jan Cieciuch, Peter Schmidt, and Jaak Billiet. 2014. "Measurement Equivalence in Cross-National Research." Annual Review of Sociology 40(1):55-75. doi: 10.1146/annurev-soc-071913-043137.

DiMaggio, Paul. 1997. "Culture and Cognition.” Annual Review of Sociology 23:263-87.

Edelmann, Achim. 2019. "Boundary Violations and Adolescent Drinking: Observational Evidence That Symbolic Boundaries Moderate Social Influence.” PLOS ONE 14(11):e0224185. doi: 10.1371/journal.pone.0224185. 
Evans, Sandra K., Katy E. Pearce, Jessica Vitak, and Jeffrey W. Treem. 2017. "Explicating Affordances: A Conceptual Framework for Understanding Affordances in Communication Research." Journal of Computer-Mediated Communication 22(1):35-52. doi: 10.1111/jcc4.12180.

Feldman, Stanley. 2013. "Political Ideology." Pp. 591-626 in The Oxford Handbook of Political Psychology, edited by L. Huddie, D. O. Sears, and J. S. Levy. New York: Oxford University Press.

Gollan, Tobias, and Erich H. Witte. 2014. "From the Interindividual to the Intraindividual Level: Is the Circumplex Model of Values Applicable to Intraindividual Value Profiles?" Journal of Cross-Cultural Psychology 45(3):452-67. doi: 10.1177/0022022113509885.

Graham, Jesse, Brian A. Nosek, Jonathan Haidt, Ravi Iyer, Spassena Koleva, and Peter H. Ditto. 2011. "Mapping the Moral Domain." Journal of Personality and Social Psychology 101(2):366-85. doi: $10.1037 / \mathrm{a} 0021847$.

Guhin, Jeffrey, Jessica McCrory Calarco, and Cynthia Miller-Idriss. 2021. "Whatever Happened to Socialization?” 21.

Healy, Kieran. 2017. “Fuck Nuance." Sociological Theory 35(2):118-27. doi: 10.1177/0735275117709046.

Henrich, Joseph. 2015. The Secret of Our Success: How Culture Is Driving Human Evolution, Domesticating Our Species, and Making Us Smarter. Princeton University Press.

Henrich, Joseph, Steven J. Heine, and Ara Norenzayan. 2010. “The Weirdest People in the World?” Behavioral and Brain Sciences 33(2-3):61-83. doi: 10.1017/S0140525X0999152X.

Henrich, Joseph, and Michael Muthukrishna. 2021. “The Origins and Psychology of Human Cooperation." Annual Review of Psychology 72(1):207-40. doi: 10.1146/annurev-psych-081920042106.

Hitlin, Steven, and Jane Allyn Piliavin. 2004. "Values: Reviving a Dormant Concept." Annual Review of Sociology 30:359-93.

Hitlin, Steven, and Stephen Vaisey. 2013. “The New Sociology of Morality." Annual Review of Sociology 39:51-68. doi: 10.1146/annurev-soc-071312-145628.

Ho, Mark K., David Abel, Thomas L. Griffiths, and Michael L. Littman. 2019. “The value of abstraction." Current Opinion in Behavioral Sciences 29:111-16. doi: 10.1016/j.cobeha.2019.05.001.

Ho, Mark K., James MacGlashan, Michael L. Littman, and Fiery Cushman. 2017. "Social Is Special: A Normative Framework for Teaching with and Learning from Evaluative Feedback." Cognition 167:91-106. doi: 10.1016/j.cognition.2017.03.006.

Iliev, Rumen, Morteza Dehghani, and Eyal Sagi. 2015. "Automated Text Analysis in Psychology: Methods, Applications, and Future Developments." Language and Cognition 7(2):265-90. doi: 10.1017/langcog.2014.30.

Inglehart, Ronald, and Wayne E. Baker. 2000. "Modernization, Cultural Change, and the Persistence of Traditional Values." American Sociological Review 65(1):19-51. doi: 10.2307/2657288.

Jerolmack, Colin, and Shamus Khan. 2009. "Where the Action Is: Ethnography and the Study of Culture" 
Jiménez, Ángel V., and Alex Mesoudi. 2019. "Prestige-Biased Social Learning: Current Evidence and Outstanding Questions.” Palgrave Communications 5(1):1-12. doi: 10.1057/s41599-0190228-7.

Joas, Hans. 2000. The Genesis of Values. Chicago, IL: University of Chicago Press.

Johnston, Christopher D., and Trent Ollerenshaw. 2020. "How Different Are Cultural and Economic Ideology?" Current Opinion in Behavioral Sciences 34:94-101. doi: 10.1016/j.cobeha.2020.01.008.

Kennedy, Brendan, Mohammad Atari, Aida Mostafazadeh Davani, Joe Hoover, Ali Omrani, Jesse Graham, and Morteza Dehghani. 2021. "Moral Concerns Are Differentially Observable in Language." Cognition 212:104696. doi: 10.1016/j.cognition.2021.104696.

Kiley, Kevin, and Stephen Vaisey. 2020. "Measuring Stability and Change in Personal Culture Using Panel Data." American Sociological Review 85(3):477-506. doi: 10.1177/0003122420921538.

Kitayama, Shinobu, and Dov Cohen, eds. 2007. Handbook of Cultural Psychology. New York: Guilford Press.

Kluckhohn, Clyde. 1951. "Values and Value-Orientations." Pp. 388-433 in Toward a General Theory of Action, edited by T. Parsons and E. A. Shils. New York: Harper and Row.

Koch, Bernard, Daniele Silvestro, and Jacob G. Foster. 2020. “The Evolutionary Dynamics of Cultural Change (As Told Through the Birth and Brutal, Blackened Death of Metal Music)." doi: 10.31235/osf.io/659bt.

Lamont, Michele. 1992. Money, Morals, and Manners: The Culture of the French and the American Upper-Middle Class. Chicago: University of Chicago Press.

Lamont, Michele, and Mario Luis Small. 2008. "How Culture Matters: Enriching Our Understanding of Poverty." Pp. 76-102 in The Colors of Poverty: Why Racial and Ethnic Disparities Persist, edited by A. Chih Lin and D. R. Harris. New York: Russell Sage Foundation.

Lareau, Annette. 2003. Unequal Childhoods: Class, Race, and Family Life. Berkeley: University of California Press.

Lee, Julie Anne, Anat Bardi, Paul Gerrans, Joanne Sneddon, Hester van Herk, Uwana Evers, and Shalom Schwartz. 2021. "Are Value-Behavior Relations Stronger Than Previously Thought? It Depends on Value Importance." European Journal of Personality 08902070211002965. doi: $10.1177 / 08902070211002965$.

Lee, Julie Anne, Joanne N. Sneddon, Timothy M. Daly, Shalom H. Schwartz, Geoffrey N. Soutar, and Jordan J. Louviere. 2019. "Testing and Extending Schwartz Refined Value Theory Using a Best-Worst Scaling Approach.” Assessment 26(2):166-80. doi: 10.1177/1073191116683799.

Lizardo, Omar. 2014. "Beyond the Comtean Schema: The Sociology of Culture and Cognition Versus Cognitive Social Science." Sociological Forum 29(4):983-89. doi: 10.1111/socf.12130.

Lizardo, Omar, Robert Mowry, Brandon Sepulvado, Dustin S. Stoltz, Marshall A. Taylor, Justin Van Ness, and Michael Wood. 2016. "What Are Dual Process Models? Implications for Cultural Analysis in Sociology." Sociological Theory 34(4):287-310. doi: 10.1177/0735275116675900. 
Longest, Kyle C., Steven Hitlin, and Stephen Vaisey. 2013. "Position and Disposition: The Contextual Development of Human Values." Social Forces 91(4):1499-1528. doi: 10.1093/sf/sot045.

Martin, John Levi, and Alessandra Lembo. 2020. “On the Other Side of Values." American Journal of Sociology 126(1):52-98. doi: 10.1086/709778.

Mesoudi, Alex. 2011. Cultural Evolution: How Darwinian Theory Can Explain Human Culture and Synthesize the Social Sciences. Illustrated edition. Chicago ; London: University of Chicago Press.

Mesoudi, Alex. 2020/ed. "Cultural Evolution of Football Tactics: Strategic Social Learning in Managers' Choice of Formation.” Evolutionary Human Sciences 2. doi: 10.1017/ehs.2020.27.

Miles, Andrew. 2015. "The (Re)genesis of Values Examining the Importance of Values for Action." American Sociological Review 80(4):680-704. doi: 10.1177/0003122415591800.

Mohr, John W., Christopher A. Bail, Margaret Frye, Jennifer C. Lena, Omar Lizardo, Terence E. McDonnell, Ann Mische, Iddo Tavory, and Frederick F. Wherry. 2020. Measuring Culture. New York: Columbia University Press.

Molleman, Lucas, Ralf H. J. M. Kurvers, and Wouter van den Bos. 2019. "Unleashing the BEAST: A Brief Measure of Human Social Information Use.” Evolution and Human Behavior 40(5):492-99. doi: 10.1016/j.evolhumbehav.2019.06.005.

Muthukrishna, Michael, Adrian V. Bell, Joseph Henrich, Cameron M. Curtin, Alexander Gedranovich, Jason McInerney, and Braden Thue. 2020. "Beyond Western, Educated, Industrial, Rich, and Democratic (WEIRD) Psychology: Measuring and Mapping Scales of Cultural and Psychological Distance." Psychological Science 31(6):678-701. doi: 10.1177/0956797620916782.

O'Connor, Cailin. 2019. The Origins of Unfairness: Social Categories and Cultural Evolution. New York: Oxford University Press.

Olson, Mancur. 1965. The Logic of Collective Action: Public Goods and the Theory of Groups. Vol. 124. Cambridge, MA: Harvard University Press.

Ostrom, Elinor. 2000. "Collective Action and the Evolution of Social Norms." The Journal of Economic Perspectives 14(3):137-58.

Oyserman, Daphna. 2017. “Culture Three Ways: Culture and Subcultures Within Countries.” Annual Review of Psychology 68(1):435-63. doi: 10.1146/annurev-psych-122414-033617.

Perry, Gina, Augustine Brannigan, Richard A. Wanner, and Henderikus Stam. 2020. "Credibility and Incredulity in Milgram's Obedience Experiments: A Reanalysis of an Unpublished Test." Social Psychology Quarterly 83(1):88-106. doi: 10.1177/0190272519861952.

Ponizovskiy, Vladimir, Murat Ardag, Lusine Grigoryan, Ryan Boyd, Henrik Dobewall, and Peter Holtz. 2020. "Development and Validation of the Personal Values Dictionary: A TheoryDriven Tool for Investigating References to Basic Human Values in Text." European Journal of Personality 34(5):885-902. doi: 10.1002/per.2294.

Schwartz, Shalom H., and Jan Cieciuch. 2021. "Measuring the Refined Theory of Individual Values in 49 Cultural Groups: Psychometrics of the Revised Portrait Value Questionnaire." Assessment 1073191121998760. doi: 10.1177/1073191121998760. 
Schwartz, Shalom H., Jan Cieciuch, Michele Vecchione, Eldad Davidov, Ronald Fischer, Constanze Beierlein, Alice Ramos, Markku Verkasalo, Jan-Erik Lönnqvist, Kursad Demirutku, Ozlem Dirilen-Gumus, and Mark Konty. 2012. "Refining the Theory of Basic Individual Values." Journal of Personality and Social Psychology 103(2):1-26. doi: 10.1037/a0029393.

Shepard, R. N. 1987. “Toward a Universal Law of Generalization for Psychological Science.” Science 237(4820):1317-23. doi: 10.1126/science.3629243.

Skyrms, Brian. 1996. Evolution of the Social Contract. New York: Cambridge University Press.

Small, Mario Luis, David J. Harding, and Michèle Lamont. 2010. "Reconsidering Culture and Poverty." The ANNALS of the American Academy of Political and Social Science 629(1):6-27. doi: $10.1177 / 0002716210362077$.

Swidler, Ann. 1986. “Culture in Action: Symbols and Strategies." American Sociological Review 51(2):273-86.

Tenenbaum, Joshua B., and Thomas L. Griffiths. 2001. "Generalization, Similarity, and Bayesian Inference." Behavioral and Brain Sciences 24(4):629-40. doi: 10.1017/S0140525X01000061.

Tenenbaum, Joshua B., Thomas L. Griffiths, and Charles Kemp. 2006. “Theory-Based Bayesian Models of Inductive Learning and Reasoning." Trends in Cognitive Sciences 10(7):309-18. doi: 10.1016/j.tics.2006.05.009.

Tenenbaum, Joshua B., Charles Kemp, Thomas L. Griffiths, and Noah D. Goodman. 2011. "How to Grow a Mind: Statistics, Structure, and Abstraction." Science 331(6022):1279-85. doi: 10.1126/science.1192788.

Thomas, W. I. 1923. The Unadjusted Girl. Boston: Little, Brown and Company.

Tormos, Raül. 2020. The Rhythm of Modernization: How Values Change over Time. Boston: Brill.

Underwood, Ted. 2019. Distant Horizons: Digital Evidence and Literary Change. University of Chicago Press.

Vaisey, Stephen. 2010. "What People Want: Poverty, Aspirations, and Educational Attainment." Annals of the American Academy of Political and Social Sciences 629:75-101. doi: $10.1177 / 0002716209357146$.

Vaisey, Stephen. 2014. “The 'Attitudinal Fallacy’ Is a Fallacy: Why We Need Many Methods to Study Culture." Sociological Methods \& Research 43(2):227-31. doi: 10.1177/0049124114523395.

Vaisey, Stephen, and Kevin Kiley. 2021. "A Model-Based Method for Detecting Persistent Cultural Change Using Panel Data." Sociological Science 8:83-95. doi: 10.15195/v8.a5.

Vaisey, Stephen, and Andrew Miles. 2014. “Tools from Moral Psychology for Measuring Personal Moral Culture." Theory and Society 43(3-4):311-32. doi: 10.1007/s11186-014-9221-8.

Vaisey, Stephen, and Lauren Valentino. 2018. "Culture and Choice: Toward Integrating Cultural Sociology with the Judgment and Decision-Making Sciences." Poetics 68:131-43. doi: 10.1016/j.poetic.2018.03.002.

Wuthnow, Robert. 2008. “The Sociological Study of Values." Sociological Forum 23(2):333-43. doi: 10.1111/j.1573-7861.2008.00063.x. 
Zerubavel, Eviatar. 1997. Social Mindscapes: An Invitation to Cognitive Sociology. Cambridge, MA: Harvard University Press. 